\title{
Estudo do comportamento e caracterização de argilas bentoníticas após processo de liofilização
}

\section{(Study of the behavior and characterization of bentonitic clays after lyophilization process)}

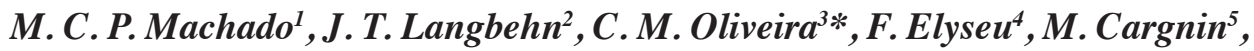 \\ A. De Noni Jr. ${ }^{1,5}$, T. E. A. Frizon ${ }^{6}$, M. Peterson ${ }^{1,5}$ \\ ${ }^{1}$ Universidade do Extremo Sul Catarinense, Programa de Pós-Graduação em Ciência e Engenharia de Materiais, \\ Criciúma, SC, Brasil \\ ${ }^{2}$ Universidade do Extremo Sul Catarinense, Departamento de Engenharia de Materiais, Criciúma, SC, Brasil \\ ${ }^{3}$ Universidade Federal de Santa Catarina, Programa de Pós-Graduação em Ciência e Engenharia de Materiais, \\ 88040-900, Florianópolis, SC, Brasil \\ ${ }^{4}$ Universidade do Extremo Sul Catarinense, Instituto de Engenharia e Tecnologia, Criciúma, SC, Brasil \\ ${ }^{5}$ Universidade do Extremo Sul Catarinense, Departamento de Engenharia Química, Criciúma, SC, Brasil \\ ${ }^{6}$ Universidade Federal de Santa Catarina, Coordenadoria Especial de Física, Química e Matemática, \\ Araranguá, SC, Brasil
}

\begin{abstract}
Resumo
Bentonita é um tipo de argila composta principalmente de montmorilonita. Possui excelentes propriedades de adsorção e como principais características a alta capacidade de troca catiônica, capacidade de inchamento, grande área superficial e baixa condutividade hidráulica. A bentonita é utilizada como matéria-prima em mais de 40 aplicações industriais. O processo de liofilização consiste na secagem de um produto, passando pela etapa de sublimação, para remoção da água contida utilizando baixa pressão e impedindo qualquer atividade biológica e reações químicas. Ele é eficiente em características como contração do produto, perda de voláteis, decomposição térmica, ações enzimáticas e desnaturação de proteínas, se comparado com outros meios de desidratação, ou seja, mantém a integridade do produto. Neste trabalho, foi avaliado o comportamento e realizada a caracterização de bentonita sódica mais ativa e sódica menos ativa, antes e após o processo de liofilização. Considerou-se como mais ativa a bentonita que apresentou maior capacidade de troca catiônica - CTC relacionada aos íons sódio $\left(\mathrm{Na}^{+}\right)$. Foram feitas análises químicas e mineralógicas, de capacidade de troca catiônica, análise microbiológica, FTIR e capacidade de inchamento. Observou-se um incremento de aproximadamente $32 \%$ na capacidade de inchamento da bentonita mais ativa após a liofilização.

Palavras-chave: bentonita, liofilização, caracterização, troca catiônica, inchamento.
\end{abstract}

\begin{abstract}
Bentonite is a type of clay composed mainly of montmorillonite, shows excellent properties of adsorption and, as main features, high cation exchange capacity, swelling capacity, large surface area and low hydraulic conductivity. Bentonite is used as a raw material in over 40 industrial applications. The lyophilization process is a drying process of a product through a sublimation step for removing water using low pressure. This process prevents any biological activity and chemical reactions. The lyophilization process is effective in product shrinkage, loss of volatiles, thermal decomposition, enzymatic activities and protein denaturation as compared to other drying means, as it maintains the integrity of the product. This study evaluated the behavior and characterized the more and less active sodium bentonites, before and after the lyophilization process. It was considered as more active the bentonite that presented more cation exchange capacity related to sodium ions $\left(\mathrm{Na}^{+}\right)$. Chemical and mineralogical analyzes, cation exchange capacity, microbiological analysis, FTIR and swelling capacity were evaluated. An increment on swelling capacity of the more active freeze-dried bentonite of approximately $32 \%$ in comparison to the standard was observed.
\end{abstract}

Keywords: bentonite, lyophilization, characterization, cation exchange, swelling.

\section{INTRODUÇÃO}

Abentonitaéummaterial argilosoconstituídobasicamente pelo argilomineral montmorilonita do grupo das esmectitas. Estes argilominerais possuem estrutura lamelar 2:1, i.e., cada lamela é constituída por duas camadas de tetraedros de sílica ligadas a uma camada central de octaedros de alumina $[1,2]$. Entre as lamelas ficam adsorvidos diferentes cátions 
que modificam a interação entre elas. $\mathrm{O}$ cátion predominante define as propriedades finais da bentonita e, por este motivo, é utilizado como critério de classificação. A presença do cátion $\mathrm{Na}^{+}$na bentonita sódica aumenta o espaçamento basal das lamelas, o que favorece maior adsorção de água se comparado ao cátion $\mathrm{Ca}^{2+}$ presente na bentonita cálcica [35]. Essa estrutura fornece ao material propriedades de grande interesse, como a capacidade de inchamento e a tixotropia [6-9]. Devido às suas características, as bentonitas possuem mais de quarenta aplicações diferentes, o que justifica a variedade de estudos realizados ao longo dos anos. Dentre elas, estão a aplicação na área de fluidos de perfuração para indústria de petróleo, clarificação de bebidas e óleos, barreiras de isolamento de resíduos radioativos e até mesmo na área farmacológica e cosmética [1, 10-15].

A utilização de minerais com fins medicinais é conhecida desde os tempos antigos, onde o uso de lamas era comum para tratamento de doenças e para irritações da pele [14, 16]. Muitos desses efeitos benéficos à saúde estão associados ao uso de bentonitas, cujas propriedades biológicas foram comprovadas em diversos estudos. Alguns trabalhos demostram sua capacidade para utilização em sistemas de entrega de drogas, como excipientes para fármacos em geral, antidiarreico e antiácidos, tratamento da dor, para a cicatrização de feridas, úlceras estomacais, bem como aplicações em cosméticos [3, 16-22]. Na área de cosméticos, as bentonitas são aplicadas em protetores solares, no tratamento de acnes e assepsia e hidratação da pele [14, 23, 24]. As argilas contêm $\mathrm{Si}, \mathrm{Al}, \mathrm{Fe}, \mathrm{Zn}, \mathrm{Mg}, \mathrm{Ca}, \mathrm{K}$ e Ti. Cada elemento contido na argila age sobre a pele de acordo com suas características. Assim sendo, o elemento ferro age como um antisséptico e como um catalisador de renovação celular; o silício como fornecimento de reconstrução de tecidos da pele, hidratação e efeito calmante; zinco e magnésio são revigorantes; cálcio e potássio agem na circulação e fortalecimento do tecido; o titânio tem característica de fotoproteção, ou seja, é um mineral capaz de refletir a radiação UV [25].

A liofilização é eficiente em características como contração do produto, perda de voláteis, decomposição térmica, ações enzimáticas e desnaturação de proteínas, se comparado com outros meios de desidratação. É um processo de estabilização no qual uma substância é previamente congelada e então a quantidade de solvente (geralmente água) é reduzida, primeiro por sublimação e posteriormente por dessorção. Esse método de secagem impede qualquer atividade biológica e reações químicas [26]. Na literatura, ao que se refere à liofilização farmacêutica, grande parte está voltada para a secagem de proteínas. Porém, pesquisas constantes estão sendo feitas a fim de investigar o uso de liofilização em várias outras aplicações nessa área [27].

Esta pesquisatem como objetivo estudaro comportamento de bentonitas sódicas após processo de liofilização, verificar a alteração de propriedades através de análise química, composição mineralógica, capacidade de troca catiônica, espectroscopia de infravermelho por transformada de Fourier, distribuição de tamanho de partícula, porosidade total e área superficial, análises térmicas, alteração da capacidade de inchamento e analisar se as argilas se enquadram nas especificações da Agência Nacional de Vigilância Sanitária (ANVISA) quanto à contaminação por bactérias mesófilas aeróbias.

\section{EXPERIMENTAL}

Preparação das amostras: para o estudo foram utilizadas duas amostras de bentonita sódica, denominadas de mais ativa e menos ativa. Essa classificação foi baseada na capacidade de troca catiônica (CTC) relacionada aos íons de sódio $\left(\mathrm{Na}^{+}\right)$das bentonitas (Tabela II), sendo mais ativa aquela com maior CTC. As amostras, fornecidas pela empresa Torrecid do Brasil, foram recebidas na forma de pó passante em peneira ABNT $200(0,074 \mathrm{~mm})$. Da quantidade disponível, parte de cada tipo foi utilizada para o processo de liofilização, sem nenhuma preparação prévia. O restante do material (amostra padrão) foi seco a $105{ }^{\circ} \mathrm{C}$ em estufa de laboratório por $24 \mathrm{~h}$ e armazenado em embalagem seca e vedada contendo envelopes de sílica gel, para garantir que a amostra não absorvesse umidade.

Processo de liofilização: o processo se deu em duas etapas. Primeiramente, as amostras foram congeladas a $-75^{\circ} \mathrm{C}$ em um ultrafreezer (Liotop, UFR30) por $24 \mathrm{~h}$. Na sequência, foram liofilizadas em um liofilizador (Liotop, L101) a uma pressão de $24 \mu \mathrm{mHg}$ por $24 \mathrm{~h}$. A temperatura do condensador se manteve em $-51{ }^{\circ} \mathrm{C}$. Após o término da liofilização, o material foi armazenado em embalagens secas e vedadas contendo envelopes de sílica gel.

Caracterização das amostras: a análise química das amostras foi realizada por espectrometria de fluorescência de raios X (FRX) em espectrômetro de raios X (Panalytical, Axios Max), com tubo de ródio. A preparação de amostra seguiu o processo de fusão de uma pérola com tetraborato de lítio para posterior leitura no equipamento. Possíveis contaminações de $\mathrm{Pb}, \mathrm{Cd}, \mathrm{Zn}, \mathrm{Cr}$ e As foram determinadas em espectrômetro de absorção atômica por chama (Thermo Scientific, ICE 3000) e a preparação das amostras seguiu procedimento de abertura normal para argilominerais. A composição mineralógica foi analisada por difração de raios X (DRX) em difratômetro (Shimadzu, XRD-6000), por meio de radiação $\mathrm{CuK} \alpha$, com $2 \theta$ variando de $3^{\circ}$ a $80^{\circ}$ nas seguintes condições: potencial de $25,0 \mathrm{kV}$, corrente de 25,0 $\mathrm{mA}$, velocidade de varredura de $2 \% \mathrm{~min}$ e passo de leitura de $0,02^{\circ}$. A capacidade de troca catiônica (CTC) foi determinada por espectrometria de absorção atômica por chama. Para a extração dos cátions trocáveis das bentonitas foi utilizada uma solução de cloreto de bário, com agitação, filtragem e posterior análise dos principais elementos sugeridos pela literatura, como cálcio, sódio, entre outros.

A espectroscopia de infravermelho por transformada de Fourier (FTIR) foi realizada em espectrofotômetro de FTIR (Shimadzu, IRAffinity-1S), utilizando o método de pastilha de KBr. Realizou-se também uma análise de FTIR acoplado, empregando um equipamento de análise térmica diferencial e termogravimétrica (DTA/TGA, Netzsch, STA 
449 F3 Jupiter), com atmosfera de ar sintético e fluxo de $80 \mathrm{~cm}^{3} / \mathrm{min}$. Esse ensaio forneceu curvas de DTA/TGA com possibilidade de análise dos gases liberados na etapa de aquecimento por leitura em FTIR (Bruker) acoplado. Para a capacidade de inchamento, $2 \mathrm{~g}$ de material foram adicionados vagarosamente durante $2 \mathrm{~h}$ em uma proveta contendo $90 \mathrm{~mL}$ de água deionizada, com posterior adição de água deionizada até a marca de $100 \mathrm{~mL}$. A medida foi retirada após $24 \mathrm{~h}$ da adição de toda a amostra, como sugere a norma ASTM D5890-11 [28]. As análises térmicas diferencial e termogravimétrica - foram realizadas com taxa de aquecimento de $20^{\circ} \mathrm{C} / \mathrm{min}$ em um DTA/TGA (Netzsch), com atmosfera de ar sintético e fluxo de $80 \mathrm{~cm}^{3} / \mathrm{min}$. Para esse ensaio, empregou-se cadinho de alumina e todas as curvas foram devidamente corrigidas, principalmente pelo efeito empuxo, que ocorre nesse tipo de equipamento que possui uma termobalança. As bentonitas foram caracterizadas também quanto à possível contaminação microbiológica. Determinou-se a contagem total de bactérias mesófilas aeróbias de acordo com norma [29].

\section{RESULTADOS E DISCUSSÃO}

Os resultados da análise química por FRX das bentonitas sódicas mais e menos ativas antes e após a liofilização (Tabela I) mostram que não houve variação significativa nas composições químicas dos principais óxidos analisados. Esse resultado já era esperado, pois o processo de liofilização não tem energia suficiente para retirar óxidos da amostra. As análises por absorção atômica não identificaram contaminação por $\mathrm{Cd}, \mathrm{Zn}, \mathrm{Cr}, \mathrm{Pb}$ e As em nenhuma das amostras.

Os difratogramas de raios X para as amostras de bentonita sódica mais ativa padrão e liofilizada encontram-se na Fig. 1. As bentonitas foram constituídas por montmorilonita

Tabela I - Análise química (\% em massa) das bentonitas. [Table I - Chemical analysis (wt\%) of bentonites.]

\begin{tabular}{ccccc}
\hline \multirow{2}{*}{ Óxido } & \multicolumn{2}{c}{$\begin{array}{c}\text { Bentonita sódica } \\
\text { mais ativa }\end{array}$} & \multicolumn{2}{c}{$\begin{array}{c}\text { Bentonita sódica } \\
\text { menos ativa }\end{array}$} \\
& Padrão & Liofilizada & Padrão & Liofilizada \\
\hline $\mathrm{Al}_{2} \mathrm{O}_{3}$ & 20,1 & 20,1 & 16,3 & 16,3 \\
$\mathrm{CaO}$ & 0,7 & 0,7 & 1,3 & 1,4 \\
$\mathrm{Fe}_{2} \mathrm{O}_{3}$ & 4,9 & 4,9 & 1,1 & 1,2 \\
$\mathrm{~K}_{2} \mathrm{O}$ & 0,4 & 0,4 & 0,3 & 0,3 \\
$\mathrm{MgO}$ & 3,4 & 3,5 & 4,7 & 4,7 \\
$\mathrm{MnO}$ & $<0,05$ & $<0,05$ & 0,06 & 0,06 \\
$\mathrm{Na}_{2} \mathrm{O}$ & 2,5 & 2,5 & 1,6 & 1,6 \\
$\mathrm{P}_{2} \mathrm{O}_{5}$ & 0,1 & 0,1 & $<0,05$ & $<0,05$ \\
$\mathrm{SiO}_{2}$ & 60,7 & 60,9 & 67,9 & 68,1 \\
$\mathrm{TiO}_{2}$ & 0,6 & 0,6 & 0,9 & 0,8 \\
$\mathrm{P.F}$ & 6,6 & 6,2 & 6,5 & 6,3 \\
\hline$F_{\text {. }}-\mathrm{P}_{2}$ & & & & \\
\hline
\end{tabular}

P.F. - perda ao fogo
(JCPDS 13-0135), ilita (JCPDS 29-1496) e quartzo (JCPDS 46-1045). A Fig. 1c mostra o pico de difração para o plano (001), que permite calcular o espaçamento basal da bentonita por meio da lei de Bragg (Eq. A) [30]. Observou-se que para a bentonita liofilizada houve pequeno deslocamento do pico para menor ângulo, indicando aumento no espaçamento basal, que foi de $9,73 \AA$ A para a amostra padrão e $9,84 \AA$ para a liofilizada.

$$
\mathrm{n} \lambda=2 \mathrm{~d} \operatorname{sen} \theta
$$

onde, $\mathrm{n}$ é um número natural, $\lambda$ é o comprimento de onda da radiação incidente, $\mathrm{d}$ é a distância entre planos atômicos e $\theta$
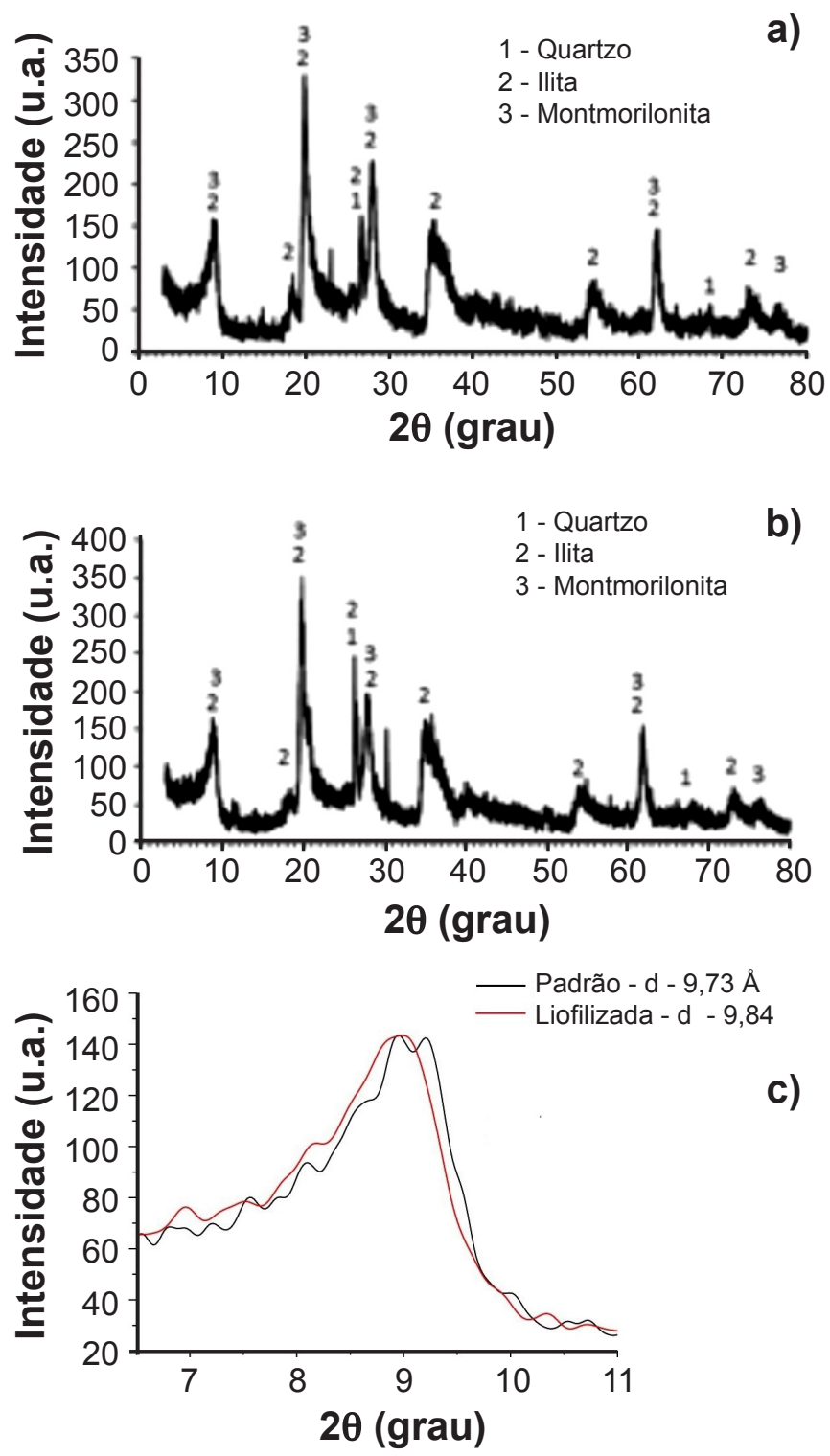

Figura 1: Difratogramas de raios $\mathrm{X}$ das bentonitas sódicas mais ativas: (a) padrão, (b) liofilizada e (c) mostrando o pico de difração do plano (001) das duas amostras.

[Figure 1: X-ray diffraction patterns of the more active sodium bentonites: (a) standard, (b) lyophilized, and (c) the diffraction peak of the plane (001) of the two samples]. 

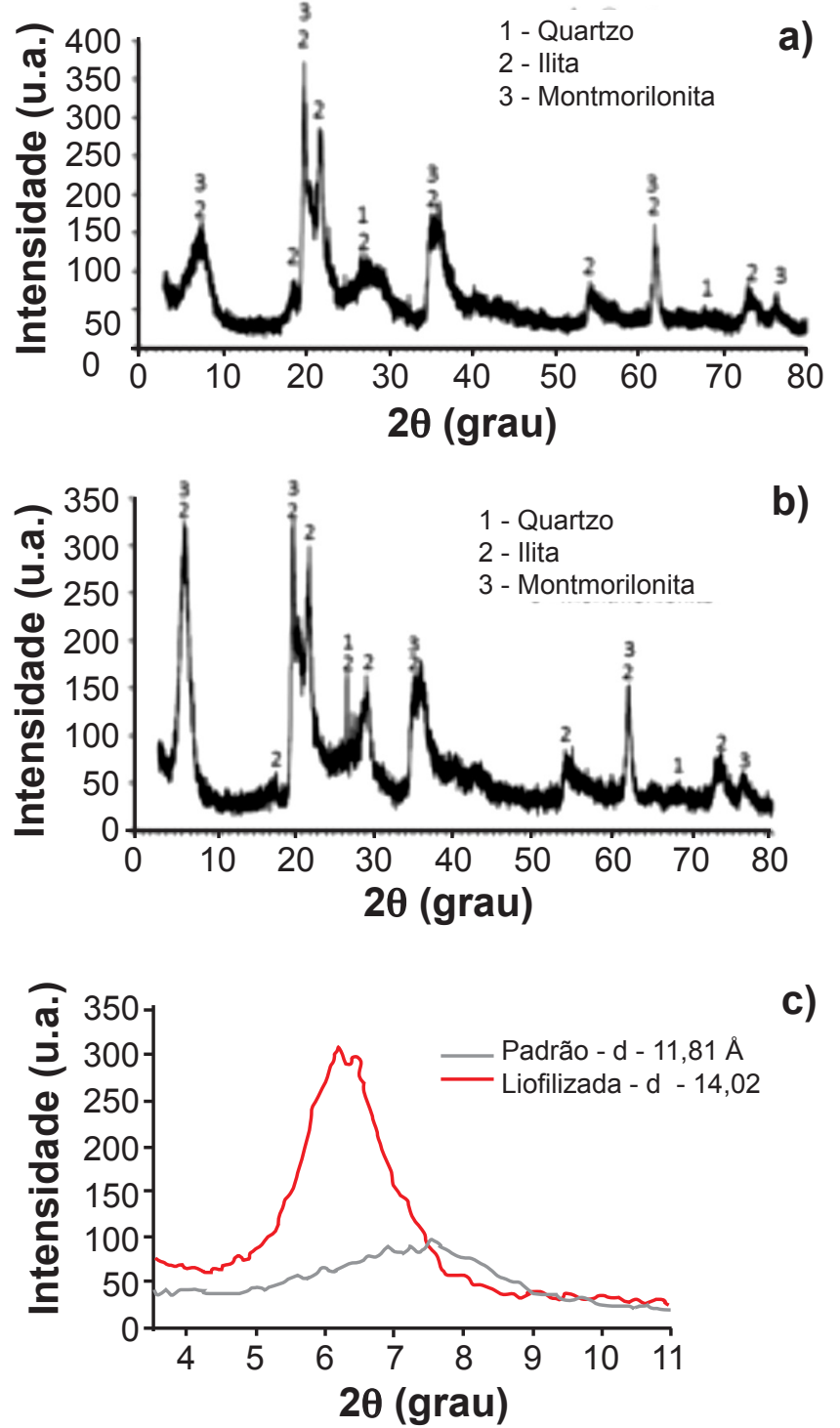

Figura 2: Difratogramas de raios $\mathrm{X}$ das bentonitas sódicas menos ativas: (a) padrão, (b) liofilizada e (c) pico de difração do plano (001) das duas amostras.

[Figure 2: X-ray diffraction patterns of the less active sodium bentonites: (a) standard, (b) lyophilized, and (c) diffraction peak of the plane (001) of the two samples].

Tabela II - Capacidade de troca catiônica (meq/100 g) das bentonitas mais e menos ativas antes e após liofilização.

[Table II - Cationic exchange capacity (meq/100 g) of the more and less active bentonites before and after lyophilization.]

\begin{tabular}{ccccc}
\hline \multirow{2}{*}{ Íon } & \multicolumn{2}{c}{$\begin{array}{c}\text { Bentonita sódica } \\
\text { mais ativa }\end{array}$} & \multicolumn{2}{c}{$\begin{array}{c}\text { Bentonita sódica } \\
\text { menos ativa }\end{array}$} \\
& Padrão & Liofilizada & Padrão & Liofilizada \\
\hline $\mathrm{Na}^{+}$ & 83,00 & 81,00 & 54,77 & 51,72 \\
$\mathrm{~K}^{+}$ & 1,10 & 1,10 & 0,24 & 0,25 \\
$\mathrm{Mg}^{2+}$ & 45,90 & 47,00 & 28,81 & 29,63 \\
$\mathrm{Ca}^{2+}$ & 21,70 & 15,30 & 10,22 & 10,17 \\
Total & 151,70 & 144,40 & 94,04 & 91,77 \\
\hline
\end{tabular}
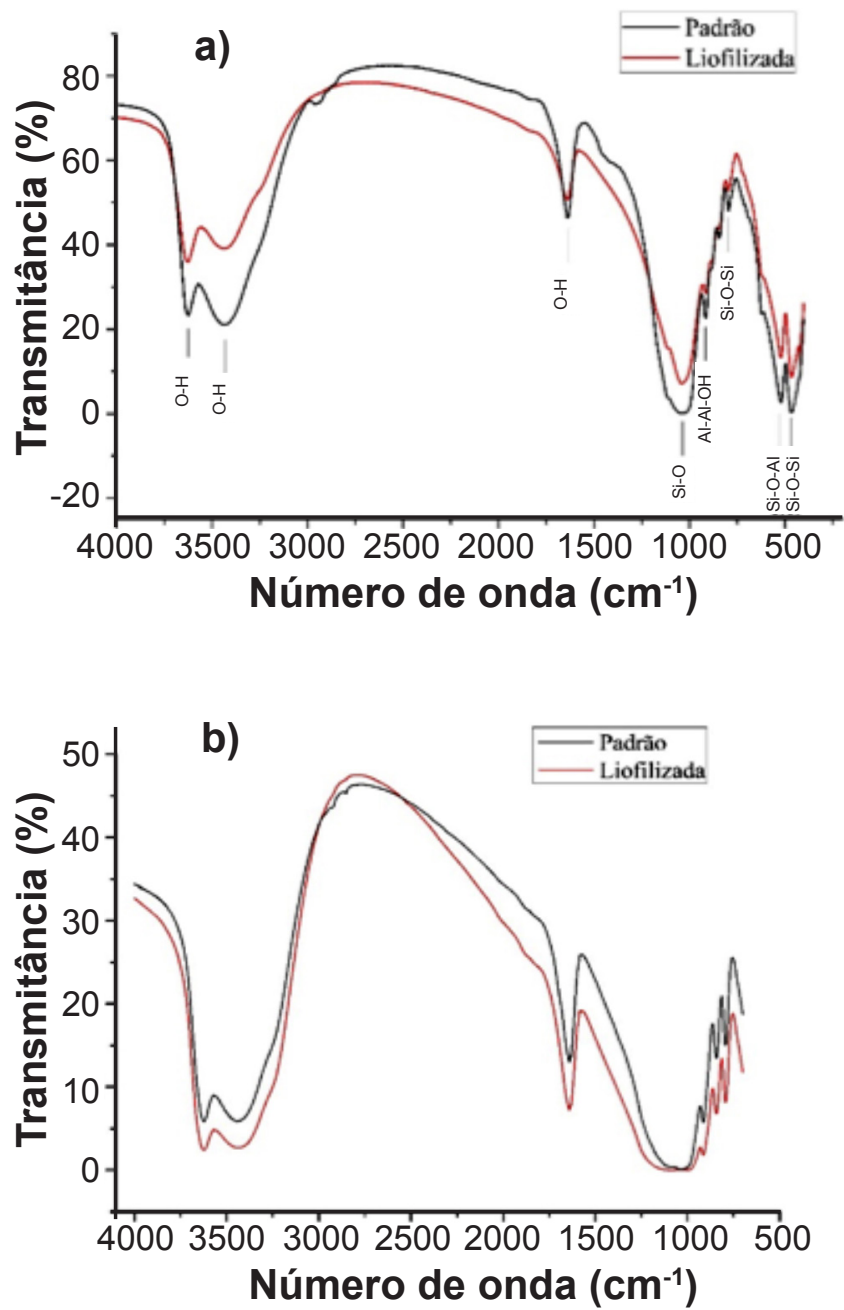

Figura 3: Espectros de FTIR das bentonitas: (a) sódica mais ativa e (b) sódica menos ativa.

[Figure 3: FTIR spectra of the more (a) and less (b) active sodium bentonites.]

é o ângulo de incidência. Os difratogramas de raios $\mathrm{X}$ das amostras de bentonita sódica menos ativa padrão e liofilizada demonstraram que elas também foram constituídas por montmorilonita, ilita e quartzo (Fig. 2). A Fig. 2c mostra que o espaçamento basal da bentonita sódica menos ativa foi maior se comparado ao da bentonita sódica mais ativa (Fig. 1c). Além disso, a liofilização também promoveu alteração no espaçamento basal, que foi de $11,81 \AA$ para a amostra padrão e 14,02 Å para a liofilizada. Embora a literatura não apresente nenhuma teoria para justificar esse aumento, acredita-se que ele seja promovido pela diferença de pressão inerente ao processo. A pressão dentro da câmara de liofilização tem valores em torno de $24 \mu \mathrm{mHg}$, praticamente vácuo absoluto, gerando um desequilíbrio de forças que pode ser responsável pelo aumento do espaçamento basal.

Na Tabela II, verifica-se que a bentonita sódica mais ativa padrão possuiu CTC de $\sim 152 \mathrm{meq} / 100 \mathrm{~g}$ de argila, com uma boa quantidade de sódio trocável, sendo este valor muito superior ao cálcio. Assim, foi possível afirmar que se trata de uma bentonita sódica. A outra amostra, com valor 

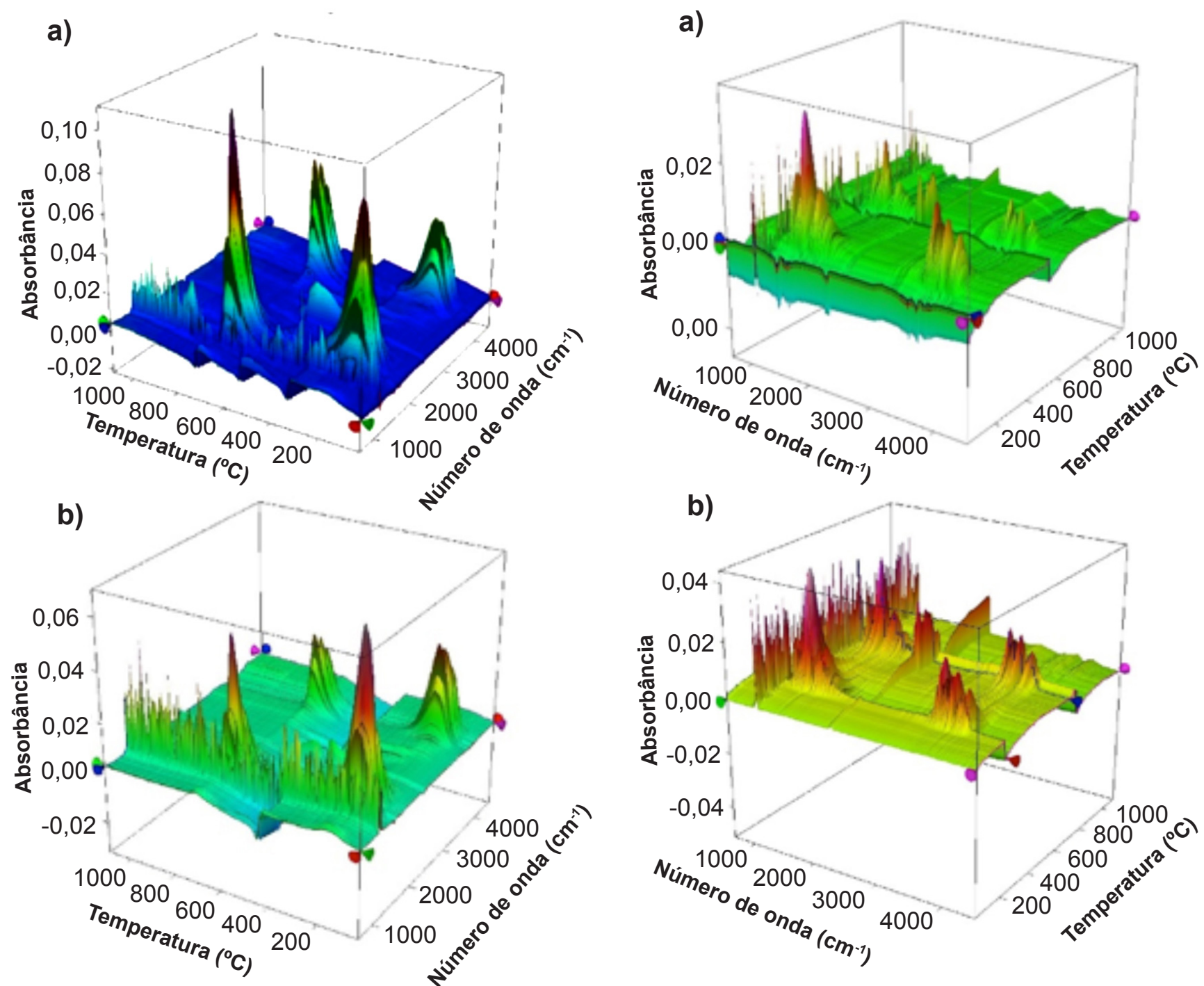

Figura 4: Espectros de FTIR acoplado das bentonitas sódicas mais ativas: (a) padrão e (b) liofilizada.

[Figure 4: Coupled FTIR spectra of the more active sodium bentonites: (a) standard, and (b) lyophilized.]

menor de CTC total ( $\sim 94 \mathrm{meq} / 100 \mathrm{~g}$ ), pode ser considerada uma bentonita sódica menos ativa, pois apresentou menor valor de troca para o cátion $\mathrm{Na}^{+}$. As duas análises são típicas de argilas bentoníticas.

Espectros de FTIR podem ser observados para as bentonitas sódicas mais e menos ativas na Fig. 3. As bandas de transmitância entre 3000 e $3700 \mathrm{~cm}^{-1}$ são características de grupos $\mathrm{OH}$. A banda presente em $1632 \mathrm{~cm}^{-1}$ corresponde à deformação dos grupos $\mathrm{OH}$ da água. A banda em $1035 \mathrm{~cm}^{-1}$ é característica da vibração da ligação Si-O na lamela. A banda localizada em $916 \mathrm{~cm}^{-1}$ é característica de ligações Al-AlOH. Em 796 e $463 \mathrm{~cm}^{-1}$ são observadas as vibrações de Si$\mathrm{O}-\mathrm{Si}$. A banda em $520 \mathrm{~cm}^{-1}$ refere-se à vibração de Si-O-Al, onde $\mathrm{Al}$ é um cátion octaédrico [3,31]. Na Fig. 3a verifica-se que a bentonita sódica mais ativa liofilizada apresenta uma menor quantidade de $\mathrm{OH}$, ou seja, menos água em relação à amostra padrão, i.e., a liofilização ocasionou uma maior retirada de água em comparação com a secagem tradicional

Figura 5: Espectros de FTIR acoplado das bentonitas sódicas menos ativas: (a) padrão e (b) liofilizada.

[Figure 5: Coupled FTIR spectra of the less active sodium bentonites: (a) standard, and (b) lyophilized.]

em estufa. Os espectros de FTIR acoplado das bentonitas sódicas mais ativas padrão e liofilizada estão representados na Fig. 4. A Fig. 5 traz os espectros das bentonitas sódicas menos ativas padrão e liofilizada. Neles, verifica-se tanto a presença dos picos de absorção do $\mathrm{OH}$ da água, presente entre as lamelas da bentonita, como também os picos de $\mathrm{OH}$ referentes água de constituição, que é liberada em altas temperaturas. Os resultados encontrados foram condizentes com aqueles obtidos pela técnica de FTIR convencional (Fig. 3).

A bentonita sódica mais ativa possuiu capacidade de inchamento superior à da bentonita sódica menos ativa (Tabela III). Essa característica provém de sua maior CTC relacionada aos íons de $\mathrm{Na}^{+}$. Esses íons ocasionam grande hidratação da bentonita [16]. Além disso, é importante ressaltar que a liofilização promoveu um incremento de $32,3 \%$ na capacidade de inchamento da bentonita sódica mais ativa. Acredita-se que o processo possa ter aumentado 
o espaçamento basal dessa argila, como observado no difratograma da Fig. 1c, mesmo ela apresentando menos água que a padrão, de acordo com o espectro de FTIR da Fig. 3a. Esse comportamento não foi observado para a bentonita sódica menos ativa. Ela demonstrou maior espaçamento basal após a liofilização (Fig. 2c), porém apresentou mais água segundo o espectro de FTIR (Fig. 3b).

Tabela III - Capacidade de inchamento das bentonitas. [Table III - Swelling capacity of bentonites.]

\begin{tabular}{cc}
\hline Amostra & $\begin{array}{c}\text { Capacidade de } \\
\text { inchamento } \\
(\mathrm{mL} / 2 \mathrm{~g})\end{array}$ \\
\hline Bentonita sódica mais ativa padrão & 31 \\
Bentonita sódica mais ativa liofilizada & 41 \\
Bentonita sódica menos ativa padrão & 10 \\
Bentonita sódica menos ativa liofilizada & 10 \\
\hline
\end{tabular}

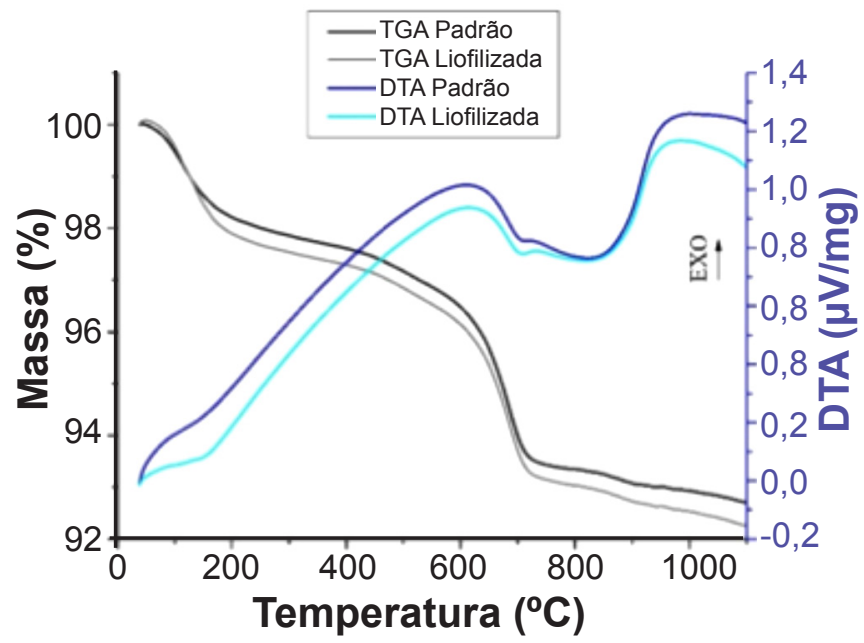

Figura 6: Curvas de DTA/TGA das bentonitas sódicas mais ativas padrão e liofilizada com taxa de aquecimento de $20^{\circ} \mathrm{C} / \mathrm{min}$.

[Figure 6: DTA/TGA curves of the standard and lyophilized more active sodium bentonites with heating rate of $20^{\circ} \mathrm{C} / \mathrm{min}$.]

Tabela IV - Análise microbiológica de contagem total de bactérias mesófilas aeróbias.

[Table IV - Microbiological analysis of total counts of aerobic mesophilic bacteria.]

\begin{tabular}{cc}
\hline Amostra & $\begin{array}{c}\text { Contagem } \\
\text { total (UFC/g) }\end{array}$ \\
\hline Bentonita sódica mais ativa padrão & 40 \\
Bentonita sódica mais ativa liofilizada & 50 \\
Bentonita sódica menos ativa padrão & 270 \\
Bentonita sódica menos ativa liofilizada & 30 \\
\hline
\end{tabular}

As análises de DTA/TGA para as bentonitas sódicas mais ativas padrão e liofilizada, com taxa de aquecimento de $20^{\circ} \mathrm{C} / \mathrm{min}$ (Fig. 6), mostraram duas regiões distintas de perda de massa que são características de bentonitas. A primeira ocorreu entre 50 e $180{ }^{\circ} \mathrm{C}$ e refere-se à perda de umidade.
A segunda ocorreu em torno de $650^{\circ} \mathrm{C}$ e correspondeu à reação de desidroxilação (pico endotérmico) [32]. Segundo a Agência Nacional de Vigilância Sanitária (ANVISA), a contagem de microrganismos mesófilos aeróbios totais não deve ultrapassar o valor de $500 \mathrm{UFC} / g$ para produtos de uso infantil, para área dos olhos e que entram em contato com mucosas, ou de $5000 \mathrm{UFC/g}$ para demais produtos cosméticos [33]. Sendo assim, as bentonitas analisadas antes e após o processo de liofilização (Tabela IV) estão aptas para utilização em cosméticos.

\section{CONCLUSÕES}

As propriedades químicas, físicas e biológicas das bentonitas foram determinadas antes e após a liofilização. A principal variação observada com o processo foi no índice de inchamento da bentonita sódica mais ativa, que teve um incremento de $32 \%$. Isso indica a possível utilização do material na fabricação de produtos com alto valor agregado, como no setor de cosméticos, onde a propriedade é tão importante ao ponto de absorver o custo da liofilização. As demais propriedades, de uma maneira geral, não apresentaram grandes mudanças. O deslocamento do pico no DRX da bentonita sódica menos ativa indicou aumento na distância entre planos cristalinos de aproximadamente 12 para $14 \AA$, decorrente da maior quantidade de água presente em sua estrutura, de acordo com o espectro de FTIR. Para a bentonita sódica mais ativa, a distância entre os planos cristalinos foi pouco afetada pela liofilização, pois apresentou menor quantidade de água, segundo o espectro de FTIR. Os resultados do ensaio de contagem total de bactérias mesófilas indicaram baixa contaminação das bentonitas, abaixo dos limites descritos da legislação da ANVISA para aplicação em cosméticos. Os valores não permitiram concluir sobre a diminuição da contagem de bactérias após o processo de liofilização.

\section{REFERÊNCIAS}

[1] H.H. Murray, Appl. Clay Sci. 17 (2000) 207.

[2] C.C. Harvey, H.H. Murray, Appl. Clay Sci. 11 (1997) 285.

[3] J. Nones, H.G. Riella, A.G. Trentin, J. Nones, Appl. Clay Sci. 105-106 (2015) 225.

[4] A. Chatterjee, F. Mizukami, A. Miyamoto, Stud. Surf. Sci. Catal. 156 (2005) 335.

[5] G. Barast, A. Razakamanantsoa, I. Djeran-Maigre, T. Nicholson, D. Williams, Appl. Clay Sci. 142 (2017) 60.

[6] P.F. Luckham, S. Rossi, Adv. Colloid Interface Sci. 82 (1999) 43.

[7] V.A. Rinaldi, J.J. Clariá Jr., Powder Technol. 291 (2016) 311.

[8] M.V. Villar, R. Gómez-Espina, L. Gutiérrez-Nebot, Appl. Clay Sci. 65-66 (2012) 95.

[9] M.Ç. Karakaya, N. Karakaya, S. Bakirb, Appl. Clay Sci. 54 (2011) 159.

[10] M.I. Abdou, A.M. Al-sabagh, M.M. Dardir, Egyptian J. 
Petroleum 22 (2013) 53.

[11] J.L. García-Siñeriz, M.V. Villar, M. Rey, B. Palacios, Eng. Geology 192 (2015) 33.

[12] E.L. Foletto, D.S. Paz, A. Gündel, Appl. Clay Sci. 8384 (2013) 63.

[13] M. Mihaljevic, V. Ettler, D. Hradil, O. Sebek, L. Strnad, Appl. Clay Sci. 31 (2006) 36.

[14] M.I. Carretero, Appl. Clay Sci. 21 (2002) 155.

[15] C. Viseras, C. Aguzzi, P. Cerezo, A. Lopez-Galindo, Appl. Clay Sci. 36 (2007) 37.

[16] F. Wypych, K.G. Satyanarayana, Clay surfaces fundamentals and applications, Elsevier (2004).

[17] C. Viseras, P. Cerezo, R. Sanchez, I. Salcedo, C. Aguzzi, Appl. Clay Sci. 48 (2010) 291.

[18] L.A.S. Rodrigues, A. Figueiras, F. Veiga, R.M. de Freitas, L.C.C. Nunes, E.C. da Silva Filho, C.M.S. Leite, Colloids Surf. B: Biointerf. 103 (2013) 642.

[19] M.I. Carretero, M. Pozo, Appl. Clay Sci. 46 (2009) 73. [20] M.I. Carretero, M. Pozo, Appl. Clay Sci. 47 (2010) 171. [21] A. Abdel-Motelib, Z.A. Kader, Y.A. Ragab, M. Mosalamy, Appl. Clay Sci. 52 (2011) 140.

[22] M.I. Carretero, M. Pozob, J.L. Legido, M.V. FernándezGonzález, R. Delgadod, I. Gómez, F. Armijo, F. Maraver,
Appl. Clay Sci. 99 (2014) 131.

[23] D.M.Z. Valenti, J. Silva, W.R. Teodoro, A.P. Velosa, S.B.V. Mello, Clin. Exp. Dermatol. 37 (2012) 164.

[24] T. Hoang-Minh, T.L. Le, J. Kasbohm, R. Gieré, Appl. Clay Sci. 53 (2011) 66.

[25] J .S . Favero, J. Parisotto-Peterle, V. Weiss-Angelib, R.N. Brandalise, L.B. Gomes, C.P. Bergmann, V. dos Santos, Appl. Clay Sci. 124-125 (2016) 252.

[26] H.C. Terroni, J.M. De Jesus, L.T. Artuzo, L.V. Ventura, R.F. Santos, P.C. Damy-Benedetti, Rev. Cient. Unilago 1 (2013) 271.

[27] J.C. Kasper, G. Winter, W. Friess, Eur. J. Pharmac. Biopharm. 85 (2013) 162.

[28] Am. Soc. Test. Mater., ASTM D5890-11 (2011).

[29] AOAC Int., AOAC 990.12 (2012).

[30] W.D.J. Callister, Ciência e engenharia de materiais: uma introdução, $7^{\text {a }}$ Ed., LTC, Rio de Janeiro (2008).

[31] L. Karimi, A. Salem, J. Ind. Eng. Chem. 17 (2011) 90. [32] K.Y. Choo, K. Bai, Appl. Clay Sci. 126 (2016) 153.

[33] ANVISA, Resol. RDC N 481, 23 set. 1999, “Estabelece os parâmetros de controle microbiológico para produtos de higiene pessoal, cosméticos e perfumes", Diário Oficial União, Brasília, DF, 27 set. 1999.

(Rec.07/07/2017, Rev. 22/08/2017, Ac. 05/09/2017) 